\section{Prolene frontalis suspension in paediatric ptosis}

K Chow, N Deva and SGJ Ng

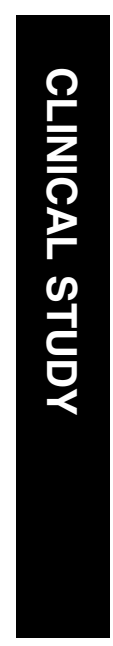

reaction, has a low risk of inducing granuloma formation and when required, can be easily removed without significant scarring.

Many non-autogenous materials are used for frontalis suspension surgery, including banked fascia lata, polyfilament nylon, Mersilene mesh, Gore-tex, and silicone. ${ }^{1-13}$ In children, such materials are often used as temporary measures until autogenous fascia lata frontalis suspension can be performed. Prolene has been shown to be an adequate temporary suspensor material for frontalis suspension in very young children, ${ }^{14}$ but other studies of prolene in ptosis surgery have reported mixed results. ${ }^{1,14-15}$

This study evaluated the functional outcome, recurrence, and complication rates of frontalis suspension using 4-0 prolene in the treatment of ptosis in children with poor levator function.

\section{Materials and methods}

A retrospective chart review of consecutive paediatric patients who underwent unilateral or bilateral frontalis suspension using 4-0 prolene from 2000 to 2008 under the care of one surgeon (SN) was performed. In all patients, the indications for surgery were levator palpebrae superioris function of less than $4 \mathrm{~mm}$ and prolonged significant occlusion of the visual axis by the ptotic lid. An additional indication in the amblyogenic age group was the presence of significant ptosis-induced astigmatism. The study excluded patients with less than 6 months' followup. Postoperative assessments were performed by one of the authors at 1 week, 1 month, and at appropriate individualised intervals thereafter. The study complied with the policies of the local institutional review board.

Data retrieved include age, gender, diagnosis, pre- and post-operative margin-to-reflex distance (MRD), pre-operative levator palpebrae superioris function, palpebral fissure height, and the post-operative parental satisfaction with cosmesis. The MRD was measured with the eyelid(s) 'at rest', that is,
Department of Ophthalmology, Waikato Hospital, Hamilton, New Zealand

Correspondence: SGJ Ng, Department of

Ophthalmology, Waikato Hospital, Private Bag 3200, Hamilton 3240,

New Zealand.

Tel.: + 6478398840

Fax: + 6478398655

E-mail: Stephen.Ng@ waikatodhb.health.nz

Received: 15 September 2010

Accepted in revised form: 19 January 2011

Published online: 4 March 2011

The results of this paper have been presented in part at the Royal Australian and New Zealand College of Ophthalmologists (RANZCO) New Zealand Branch Annual Meeting, May 2009.

There was no financial support or conflict of interest regarding this study. 
when the patient was not actively contracting their frontalis muscles. Functional success was defined by fulfilling the following three criteria:

1. Satisfactory lid height (defined as $M R D \geq 3 \mathrm{~mm}$ ).

2. Satisfactory lid symmetry $(\leq 2 \mathrm{~mm}$ asymmetry in MRD).

3. Parental satisfaction with the cosmetic outcome.

Recurrence was defined by a drop in lid height of $\geq 3 \mathrm{~mm}$ from the initial post-operative level. Post-operative eyelid or ocular complications were also noted.

\section{Operative procedure}

The surgical method was based on the modified Fox pentagon technique. ${ }^{16}$ All operations were performed under general anaesthesia as day cases. After induction of general anaesthesia, skin incisions on the upper lid and brow were marked. Local anaesthetic with adrenaline was injected around these sites and subcutaneously along the tracks of the sutures. A traction suture was inserted into the upper lid. A lubricated spatula was used to protect the eye. A 4-0 prolene suture was passed transversely, partial thickness, through the upper lid tarsal plate. The needle of the prolene suture was then removed. A Wright's needle was then used to thread the suture through the subcutaneous tissue of the lid and brow. When the lid height and contour were judged to be satisfactory, the suture was tied and then buried in the forehead subcutaneous tissue. The forehead skin wounds were then closed with a 7-0 polyglactin suture. Postoperatively, ocular ointments were applied to the eye four times a day for up to 1 week. Thereafter the use of the ointments was tapered according to the degree of irritation and redness of the child's eye(s). Oral paracetamol was used as required for analgesia.

\section{Statistical analysis}

To satisfactorily describe the results of unilateral and bilateral cases, both 'eyelid' and 'patient' were used as the units of analysis. Fisher's exact tests were performed to detect any significant differences in proportions.

\section{Results}

In total, 25 children underwent prolene frontalis suspension surgery during the study period. Overall, 23 were included in the study and 2 were excluded because of insufficient follow-up duration. Seven patients had bilateral surgery, giving a total of 30 eyelids. The mean follow-up was $28.7 \pm 22.6$ months (range 6.3 to 100.0 months). Table 1 summarises the characteristics of
Table 1 Baseline characteristics of patients included in the study

\begin{tabular}{lc}
\hline No. of patients & 23 (30 eyelids) \\
Gender (male/female) & $13 / 10$ \\
& \\
Age at surgery (months) & $22.0 \pm 22.7$ \\
$\quad$ Mean \pm SD & $0.6-96.0$ \\
Range & \\
Follow-up (months) & $28.7 \pm 22.6$ \\
Mean \pm SD & $6.3-100.0$ \\
Range & \\
& \\
Diagnosis & 17 \\
Congenital myogenic ptosis & 5 \\
Blepharophimosis syndrome & 1 \\
Marcus Gunn jaw-winking ptosis & \\
\hline
\end{tabular}

the study population. Table 2 describes the individual patient data of the study population.

Table 3 summarises the study results. Both 'eyelid' and 'patient' were used as units of analysis and the results were compared. Of the 30 eyelids, in the follow-up period, 23 (77\%) achieved functional success. Due to lid height asymmetry, functional success was not achieved in one child (patient no. 14, Table 2) who underwent bilateral surgery. Ptosis recurred in five eyelids (17\%), requiring revision surgery. Four of the five recurrences occurred within the first 5 months after the operation. The causes of these early recurrences were: indeterminate in one child, one from knot failure, and two from suture breakage from direct trauma (children hitting their heads when playing). One recurrence occurred 19 months postoperatively without an identified cause. The complication rate was $3.3 \%$, with one lid developing mild redness after surgery that was regarded as a wound infection. This was treated by the child's general practitioner with oral antibiotics, and resolved within a few days without long-term sequelae.

When 'patient' was used as the unit of analysis, there were fewer units for analysis because of the seven bilateral cases. In this analysis, the functional success rate was slightly lower at $74 \%(17 / 23)$, the ptosis recurrence rate was slightly higher at $22 \%(5 / 23)$, and the complication rate was $4 \%(1 / 23)$ (Table 3$)$. The differences between the results of the two analytical approaches were not statistically significant $(P>0.05$, Table 3$)$.

\section{Discussion}

To the best of our knowledge, this is the largest series with the longest follow-up reported for prolene frontalis suspension in children. The efficacy of prolene frontalis suspension observed in our study is comparable to that reported for other materials (Table 4). Our ptosis recurrence 
Table 2 Individual patient characteristics and outcomes of prolene frontalis suspension

\begin{tabular}{|c|c|c|c|c|c|}
\hline Patient no. & Left/right & Ptosis aetiology & Age at surgery & $\begin{array}{l}\text { Follow-up } \\
\text { (months) }\end{array}$ & Functional success \\
\hline 1 & Bilateral & Congenital & 1 year 1 month & 17 & Yes \\
\hline 2 & Bilateral & Blepharophimosis syndrome & 18 days & 19 & Yes \\
\hline 3 & Left & Congenital & 3 months & 20 & Yes \\
\hline 4 & Right & Congenital & 10 months & 26 & Yes \\
\hline 5 & Right & Congenital & 1 year 11 months & 42 & Yes \\
\hline 6 & Left & Congenital & 2 years 10 months & 49 & yes \\
\hline 7 & Bilateral & Blepharophimosis syndrome & 2 years 11 months & 52 & Yes \\
\hline 8 & Bilateral & Blepharophimosis syndrome & 1 year 5 months & 53 & Yes \\
\hline 9 & Right & Congenital & 8 years & 13 & Yes \\
\hline 10 & Bilateral & Blepharophimosis syndrome & 3 years 1 month & 13 & No (left ptosis recurred at 1 month, revised) \\
\hline 11 & Left & Congenital & 2 years 5 months & 18 & No (ptosis recurred at 7 days, revised) \\
\hline 12 & Left & Congenital & 2 years 2 months & 32 & No (ptosis recurred at 5 months, revised) \\
\hline 13 & Left & Congenital & 1 year & 47 & No (ptosis recurred at 19 months) \\
\hline 14 & Bilateral & Blepharophimosis syndrome & 8 months & 11 & $\begin{array}{l}\text { No (significant lid height asymmetry } \\
\text { post-operation, revised) }\end{array}$ \\
\hline 15 & Right & Congenital & 1 year 11 months & 23 & Yes \\
\hline 16 & Bilateral & Congenital & 1 year 2 months & 100 & No (right ptosis recurred at 2 days, revised) \\
\hline 17 & Right & Congenital & 2 months & 58 & Yes \\
\hline 18 & Left & Congenital & 1 month & 14 & Yes \\
\hline 19 & Left & Marcus Gunn jaw-winking & 6 years & 12 & Yes \\
\hline 20 & Left & Congenital & 2 years 1 month & 16 & Yes \\
\hline 21 & Right & Congenital & 10 months & 8 & Yes \\
\hline 22 & Left & Congenital & 8 months & 6.5 & Yes \\
\hline 23 & Left & Congenital & 8 months & 10 & Yes \\
\hline
\end{tabular}

Table 3 Functional success, recurrence and other complications after prolene frontalis suspension

\begin{tabular}{llll}
\hline & Eyelid $(\mathrm{n}=30)$ & Patient $(\mathrm{n}=23)$ & P-value \\
\hline Functional success & $23(77 \%)(95 \%$ CI: 59-89\%) & $17(74 \%)(95 \%$ CI: 53-89\%) & 1 \\
Ptosis recurrence & $5(17 \%)(95 \%$ CI: 6-33\%) & $5(22 \%)(95 \%$ CI: 8-42\%) & 0.73 \\
$\begin{array}{l}\text { Complications } \\
\quad \text { Exposure keratopathy }\end{array}$ & 0 & 0 & 1 \\
$\quad$ Wound infection & $1(3.3 \%)$ & $1(4 \%)$ & 1 \\
\hline
\end{tabular}

Table 4 Comparison of ptosis recurrence and other complications with published data of other suspension materials ${ }^{\mathrm{a}}$

\begin{tabular}{|c|c|c|c|c|c|}
\hline & $\begin{array}{l}\text { Recurrence } \\
\text { rate }(\%)\end{array}$ & $\begin{array}{c}\text { Exposure keratopathy } \\
\text { rate }(\%)\end{array}$ & $\begin{array}{c}\text { Infection/granuloma } \\
\text { rate }(\%)\end{array}$ & No. of eyelids & $\begin{array}{c}\text { Mean/median } \\
\text { follow-up (months) }\end{array}$ \\
\hline Autogenous fascia lata ${ }^{17}$ & 1 & - & - & 324 & 18 \\
\hline Banked fascia lata ${ }^{3}$ & 35 & - & 6 & 40 & 24 \\
\hline Polyfilament nylon ${ }^{19}$ & 28 & 0 & 12 & 121 & 31.5 \\
\hline Mersilene mesh ${ }^{9}$ & 27 & 0 & 18 & 20 & 31 \\
\hline Gore-tex $^{13}$ & 20 & 2.5 & 5 & 40 & 25 \\
\hline Silicone $^{12}$ & 23 & 0 & - & 77 & 32.5 \\
\hline Prolene (current study) & 22 & 0 & 4 & 30 (23 patients) & 28.7 \\
\hline
\end{tabular}

aStudies included are limited to those with at least 20 eyelids for one particular material and at least 18 months mean or median follow-up.

rate was $22 \%$. The three previous studies of prolene in ptosis surgery had recurrence rates between 12.5 and $50 \% .114,15$ Our recurrence rate was higher than most studies using autogenous fascia lata, but is comparable to that of all previously studied non-autogenous materials (Table 4).
In paediatric ptosis surgery, prolene has been perceived as a temporizing material to be used until autogenous fascia lata frontalis suspension can be performed. However, for the majority of cases in our series, prolene frontalis suspension has provided a 
sustained effect leading to indefinite postponement of autogenous fascia lata frontalis suspension surgery.

The low complication rate noted in our series is better than most other studies. Suture extrusion rates in other studies have been reported between 5 and $17 \% .^{6}$ This complication was not seen in our study. This may reflect the ease of burying prolene sutures within the subcutaneous tissues and its low tissue reactivity.

Direct comparison of success rates in studies of materials used in frontalis suspension surgery is difficult because there is considerable variation in outcome measures used in different studies. ${ }^{1-12,17,18}$ We measured the MRD with the eyelid(s) 'at rest'. This provides an objective, albeit conservative, outcome measure. In fact, patients who have undergone frontalis suspension surgery can increase their MRD significantly by voluntarily or involuntarily contracting their frontalis muscles when they are attentive or concentrating on a task.

Many previous studies have used 'eyelid' as their unit of analysis. ${ }^{1-3,6,7,10,19}$ When analysing our study results, the use of 'eyelid' rather than 'patient' as the study unit gave a higher success rate and a lower recurrence rate, though the differences were not statistically significant. This difference may represent the potential bias introduced by the 'eyelid' analysis approach. Lid symmetry is generally easier to achieve in bilateral than unilateral ptosis surgery. Failure to account for bilateral cases when using 'eyelid' as the unit of analysis will inflate the sample size, and overestimate the success rate and statistical power. In contrast, analysis using 'patient' as the study unit may produce more accurate results.

In the age group we studied, we concentrated on surgery to maximise visual development. In general, cosmetic considerations were postponed until children were beyond the amblyogenic age. Revision surgery using autogenous fascia lata was offered when children were beyond this age. In children with unilateral ptosis, parents were given information on the options of unilateral or bilateral surgery. The options would then be individualised according to the wishes of the family. During the study period, none of the children went on to require revision surgery with autogenous fascia lata. One 8-month-old child with blepharophimosis syndrome and bilateral ptoses who underwent bilateral prolene frontalis suspension surgery resulting in significant eyelid height asymmetry, later underwent revision of one eyelid with prolene.

Although not addressed in this study, prolene is an ideal material in patients undergoing ptosis surgery who have orbicularis oculi weakness and who are at risk of postoperative exposure keratopathy. Prolene sutures can be readily located under the lid skin. The minimal tissue reactivity induced by prolene means that cutting or removing it easily reverses the effect of the frontalis suspension. In older patients, this can be performed under local anaesthesia in the clinic. In contrast, materials such as fascia lata and Mersilene mesh may not be easily removed. ${ }^{20}$

Limitations of our study are its retrospective design and the possibility that more recurrences may occur with longer follow-up.

Prolene frontalis suspension is an effective technique for the treatment of paediatric ptosis with poor levator function. It is a readily available and inexpensive material that is easy to insert. Its results, complication, and recurrence rates are very favourable when compared with other non-autogenous materials.

\section{Summary}

What was known before

- Non-autogenous materials have been used for frontalis suspension surgery in paediatric ptosis patients. Prolene has been shown to be a potentially suitable temporary material for frontalis suspension. However, past studies of prolene frontalis suspension were limited to a few small case series with conflicting results.

What this study adds

- Prolene frontalis suspension has good efficacy and an excellent safety profile in paediatric ptosis with poor levator function. Its results compare favourably with those of other non-autogenous materials. To the best of our knowledge, this is the largest study with the longest follow-up for prolene frontalis suspension to date.

\section{Conflict of interest}

The authors declare no conflict of interest.

\section{References}

1 Wasserman BN, Sprunger DT, Helveston EM. Comparison of materials used in frontalis suspension. Arch Ophthalmol 2001; 119(5): 687-691.

2 Hersh D, Martin FJ, Rowe N. Comparison of silastic and banked fascia lata in pediatric frontalis suspension. J Pediatr Ophthalmol Strabismus 2006; 43(4): 212-218.

3 Whitehouse GM, Grigg JR, Martin FJ. Congenital ptosis: results of surgical management. Aust N Z J Ophthalmol 1995; 23(4): 309-314.

4 Wilson ME, Johnson RW. Congenital ptosis. Long-term results of treatment using lyophilized fascia lata for frontalis suspensions. Ophthalmology 1991; 98(8): 1234-1237.

5 Esmaeli B, Chung H, Pashby RC. Long-term results of frontalis suspension using irradiated, banked fascia lata Ophthal Plast Reconstr Surg 1998; 14(3): 159-163.

6 Ben Simon GJ, Macedo AA, Schwarcz RM, Wang DY, McCann JD, Goldberg RA. Frontalis suspension for upper eyelid ptosis: evaluation of different surgical designs and suture material. Am J Ophthalmol 2005; 140(5): 877-885.

7 Liu D. Blepharoptosis correction with frontalis suspension using a supramid sling: duration of effect. Am J Ophthalmol 1999; 128(6): 772-773. 
8 Hintschich CR, Zurcher M, Collin JR. Mersilene mesh brow suspension: efficiency and complications. Br J Ophthalmol 1995; 79(4): 358-361.

9 Mehta P, Patel P, Olver JM. Functional results and complications of Mersilene mesh use for frontalis suspension ptosis surgery. $\mathrm{Br}$ J Ophthalmol 2004; 88(3): 361-364.

10 Carter SR, Meecham WJ, Seiff SR. Silicone frontalis slings for the correction of blepharoptosis: indications and efficacy. Ophthalmology 1996; 103(4): 623-630.

11 Fogagnolo P, Serafino M, Nucci P. Stability of silicone band frontalis suspension for the treatment of severe unilateral upper eyelid ptosis in infants. Eur J Ophthalmol 2008; 18(5): 723-727.

12 Lee MJ, Oh JY, Choung HK, Kim NJ, Sung MS, Khwarg SI. Frontalis sling operation using silicone rod compared with preserved fascia lata for congenital ptosis a three-year follow-up study. Ophthalmology 2009; 116(1): 123-129.

13 Wei YH, Liao SL. Frontalis suspension using expanded polytetrafluoroethylene: results of different surgical designs. J Formos Med Assoc 2009; 108(12): 943-949.
14 Manners RM, Tyers AG, Morris RJ. The use of Prolene as a temporary suspensory material for brow suspension in young children. Eye (Lond) 1994; 8(Part 3): 346-348.

15 Garrott H, Aristodemou P, Sinclair N, Lane C, Harrad R. Long-term efficacy of 2-0 Prolene brow suspensions for congenital ptosis. Eye (Lond) 2010; 24(1): 175-177.

16 Fox SA. Congenital ptosis. II. Frontalis sling. J Pediatr Ophthalmol 1966; 3: 25-28.

17 Yoon JS, Lee SY. Long-term functional and cosmetic outcomes after frontalis suspension using autogenous fascia lata for pediatric congenital ptosis. Ophthalmology 2009; 116(7): 1405-1414.

18 Deenstra W, Melis P, Kon M, Werker P. Correction of severe blepharoptosis. Ann Plast Surg 1996; 36(4): 348-353.

19 Wagner RS, Mauriello Jr JA, Nelson LB, Calhoun JH, Flanagan JC, Harley RD. Treatment of congenital ptosis with frontalis suspension: a comparison of suspensory materials. Ophthalmology 1984; 91(3): 245-248.

20 Morris CL, Buckley EG, Enyedi LB, Stinnett S, Freedman SE. Safety and efficacy of silicone rod frontalis suspension surgery for childhood ptosis repair. J Pediatr Ophthalmol Strabismus 2008; 45(5): 280-288; quiz 289-290. 